BULL. AUSTRAL. MATH. SOC.

$92 \mathrm{~A} 10$

VOL. 19 (1978), 141-142.

\title{
One- and two-locus inbreeding for recurrent selection and overlapping generations selection schemes
}

\section{Sam Choy}

Inbreeding coefficients at one and two loci are evaluated for recurrent selection and overlapping generations selection schemes. These mating schemes have found great use in plant and animal breeding. The inbreeding coefficients are derived in terms of probability measures that genes are identical by descent. The procedures demonstrated here can be applied to any regular system of mating between individuals or groups of individuals.

For individual mating systems, two digametic individual measures are defined and employed in the derivation of a recurrence formula for the onelocus inbreeding coefficients. Two further classes of individual measures, trigametic and quadrigametic, are required for transition from one generation to the previous one to allow the calculation of the inbreeding coefficients for the two-locus case. This process is illustrated for the case of recurrent selection. For recurrent selection populations with various imposed assumptions, numerical values of the average inbreeding coefficients at the end of the breeding cycles are listed to demonstrate the effects of linkage and population size on the accrual of inbreeding and hence of homozygosity.

For group mating systems, gametic set measures are needed in addition to the average individual measures. Transition equations relating values in successive generations of gametic set measures are established for the calculation of the group inbreeding coefficients. As an illustration of this process, the one- and two-locus inbreeding coefficients for

Received 23 August 1978. Thesis submitted to Massey University, February 1978. Degree approved, August 1978. Supervisors: Dr B.S. Weir, Professor B.I. Hayman, Professor A.L. Raẹ. 
populations with overlapping generations are evaluated. Both monoecious and dioecious populations of diploids are considered and family size is not restricted to being Poisson. Inbreeding effective numbers found by the exact treatment here are compared to various previous approximate results. 